\title{
Health economics: the end of clinical freedom?
}

\author{
Alan Williams
}

“... doctors are not perfect agents, and because of that they discretion over what they take into account in exercising their so called 'clinical' judgment, so that the distinction between 'strictly clinical' and 'extraneous' factors is a fuzzy one..." have quite a lot of

"Clinical freedom is dead, and no one need regret its passing. Clinical freedom was the right-some seemed to believe the divine right - of doctors to do whatever in their opinion was best for their patients. In the days harmless as it was ineffective the doctor's opinion was all that there was, but now opinion is not good enough. If we do not have the resources to do all that is technically possible then medical care must be limited to what is of proved value, and the medical profession will have to set opinion aside.

"Clinical freedom died accidentally, crushed between the rising cost of new forms of investigation and treatment and the financial limits inevitable in an economy that cannot expand indefinitely. Clinical freedom should, however, have been strangled long ago, for at best it was a cloak for ignorance and at worst an excuse for quackery. Clinical freedom was a myth that prevented true advance. We must welcome its demise, and seize the opportunities now laid out before us."

So wrote John Hampton, an eminent professor of cardiology, in the $B M \mathcal{F}$ in October $1983 .{ }^{1}$ I think his rather unkind obituary notice for clinical freedom was in fact premature, for if indeed clinical freedom is dead it seems reluctant to lie down. It is still frequently paraded before us (rather as with the corpse of El Cid?) in defence of some medical practice which is being challenged by a non-medical person on grounds of its doubtful effectiveness, or its undoubtedly high cost, or both.

A sharply contrasting view to Hampton's was expressed a few years earlier in a letter to the New England Fournal Medicine by a doctor practising in New York State. ${ }^{2}$ He wrote: "Of late an increasing number of papers in this and other journals have been concerned with 'cost-effectiveness' of diagnostic and therapeutic procedures. Inherent in these articles is the view that choices will be predicated not only on the basis of strictly clinical considerations but also on economic considerations as they may affect the patient, the hospital, and society. It is my contention that such considerations are not germane to ethical medical practice. ... A physician who changes his or her way of practising medicine because of cost rather than purely medical considerations has indeed embarked on the 'slippery slope' of compromised ethics and waffled priorities."

\section{Polar positions}

Although prudence suggests that it is better for outsiders like me to remain onlookers when it comes to intraprofessional disputes of this degree of intensity and on topics of this degree of sensitivity, economists are not noted for angelic reticence so I propose to join the other fools from outside the medical profession and rush into the fray.

Before getting too deeply embroiled, however, let me state the issue as sharply as possible so that there is no doubt as to what the fuss is all about. The two polar positions are as follows:

Viewpoint $A-$ It is the doctor's duty to do all he or she can for the patient no matter what the cost.

Viewpoint $B-$ It is the doctor's duty to take costs

Institute for Research in the Social Sciences, University of York, York YO1 5DD Alan Williams, professor of economics

into account when deciding what course of action to recommend for the patient.

There are various ways forward when faced with this when investigation was non-existent and treatment as

sharp difference of view. The conservative view would be that the quest for efficiency, or cost consciousness, must stop as soon as it begins to breach clinical freedom (which may mean that the quest can never really start). A more radical view would be that if clinical freedom stands in the way of cost effectiveness then it is clinical freedom that must go (unless of course, as Hampton believes, it has already gone).

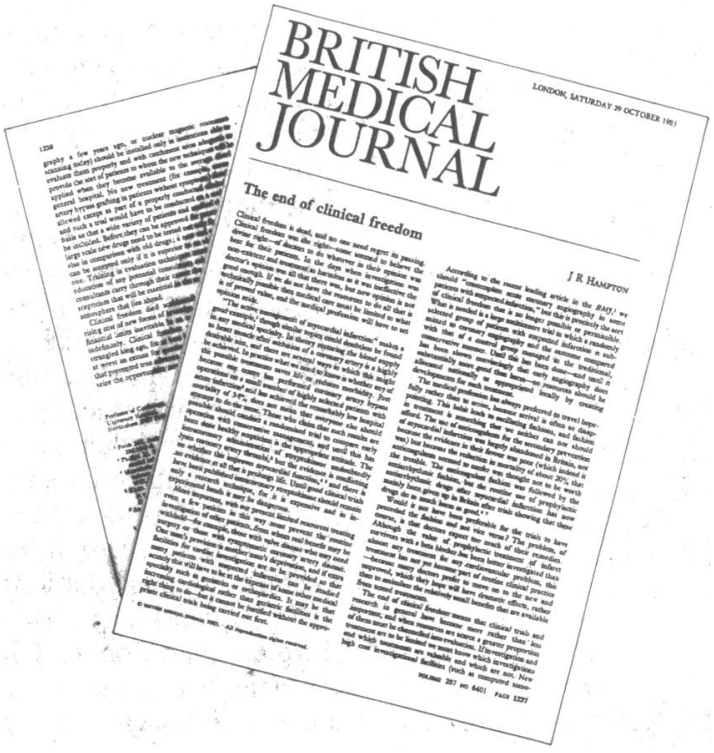

A middle of the road view might be that all that is necessary is that the essence of clinical freedom is better understood, and when it is redefined according to that better understanding the apparent conflict will disappear. This seems to be the stance of the current president of the Royal College of Physicians, Sir Raymond Hoffenberg, to whose views (as expressed in his recent monograph on clinical freedom ${ }^{3}$ ) I will return later.

But before considering his position I want to develop one of my own, which is essentially that despite their protestations to the contrary doctors never have behaved without regard to the costs of their actions. Simply stated, they have been selective and haphazard about what costs they counted and how they counted them. So the issue is not whether or not it is ethical to count costs but rather where the line should be drawn between costs that may be counted and costs that may not.

To capture the essence of the situation it is important to focus on the nature of the relationship between doctor and patient. In theory the patient and the doctor are in a principal-agent relationship in which the doctor is the agent and the patient is the principal. If the doctor were a perfect agent their relationship would then be as follows:

The DOCTOR is there to give the PATIENT all the information the PATIENT needs in order that the PATIENT can make a decision, and the DOCTOR should then implement that decision once the PATIENT has made it.

If you find that description of your relationship with your patient a bit odd try reversing the respective roles of the doctor and the patient so that it now reads:

The PATIENT is there to give the DOCTOR all the information the DOCTOR needs in order that the 
If $I$ am right in $m y$ diagnosis the immediate task of health economists is to get our notions of efficiency and fairness in the distribution of the benefits of health care so deeply embedded in the clinical consciousnes that they come to be thought of as wholly within the realm of clinical autonomy. ..
DOCTOR can make a decision, and the PATIENT should then implement that decision once the DOCTOR has made it.

Does that sound more like it actually is? The point is that doctors are not perfect agents, and because of that they have quite a lot of discretion over what they take into account in exercising their so called "clinical" judgment, so that the distinction between "strictly clinical" and "extraneous" factors is a fuzzy one, as we shall see later when considering Hoffenberg's views.

\section{Economic considerations}

For now let me illustrate these points with three examples, designed to show that doctors have, quite spontaneously, had regard to "economic considerations as they may affect the patient, the hospital, and society," notwithstanding what the American doctor believes. Moreover, they have absorbed these considerations comfortably within what they would still regard as their own clinical judgment rather than as part of any wider "extraneous" economic or social responsibility.

The first example concerns a patient for whom there are two possible courses of treatment, the safer and more effective of which would require the patient to be off work for three months, entailing a substantial loss of income for him and possibly putting his livelihood in jeopardy altogether. The less safe and less effective treatment entails no such risks. Which treatment do you think most doctors would offer in that situation? Would they regard it as unethical to consider these "economic considerations as they affect the patient?"

The second example concerns a patient with a stable chronic condition that has already been thoroughly investigated and is being treated conventionally. The patient has seen a TV programme describing some research which seems to suggest that a new drug works wonders for some patients with that condition, and the patient wants to be sent for investigation at the nearby regional centre where the TV programme was made. Both the patient and the doctor know that there is only a small chance that the patient will benefit, and in any case this would be a very expensive course of action for everybody. The doctor also knows that the specialist in question takes a poor view of general practitioners who send him speculative cases lacking clear indications that such referral is justified, and that the regional centre is hard pressed to cope with its workload as it is. What do you think most doctors would do in that situation? Would they regard it as unethical to take into account these "economic considerations as they affect the hospital?"

The final example concerns an elderly woman living with relatives whose daughter has had to switch from full time to part time work to cope with the strain of looking after her, who disturbs the neighbours with her odd behaviour, and who is costing the health and personal social services a great deal of money in domiciliary support. Although it is acknowledged that the patient's own survival prospects and quality of life will be worse if she is taken into hospital, those around her will certainly be better off, and it will release a lot of scarce domiciliary support for others to use. What do you think most doctors would do in that situation? Would they regard it as unethical to take into account "economic considerations as they affect society" - that is, people other than the patient?

It is the observation of clinical behaviour in examples such as these that convinces me that doctors do not regard it as unethical to have regard to costs, whether these costs fall on patients, their relatives, the health service, or the community at large. And I do not regard their characteristic behaviour in each of the examples I cited as at all unreasonable. I am sure that we ordinary citizens, and indeed the courts of law, would support them in their decisions if they were challenged.

\section{Ghost of clinical freedom}

So why is clinical freedom (or, if Hampton is right, the ghost of clinical freedom) invoked when economists argue that clinicians should count costs when making treatment decisions? I suppose it may simply be that insiders are allowed to say things about each other which none of them would allow an outsider to say. After all, if you give these economists an inch they'll take an ell, and before you know where you are there will be a desiccated inhuman calculator in every consulting room.

Time to send for Raymond Hoffenberg. I fear that his testimony will not help the scaremongers very much. Early on in his monograph ${ }^{3}$ he observes: "There is no such thing as clinical freedom, nor has there ever been. Nor, for that matter, should there be.... Absolute freedom to make clinical decisions without taking into account the preferences or wishes of the patient could not be countenanced. It is therefore proper that personal, moral, ethical and even legal constraints should be observed. To these must now be added the constraint of limited resources."

Later he notes that this additional constraint requires doctors to help in rationing access to health care and asks: "Does acceptance of this function compromise our clinical freedom? It is not easy to identify or isolate the part played by awareness of costs when individual doctors ... decide whether or not to investigate or treat a patient. The open and direct opinion 'This would cost too much,' is rarely expressed and, I suspect, not often consciously entertained as a discretionary factor. Even if it were it would be regarded simply as one of the factors that needed to be taken into account in order to establish a course of action. It would not often be seen as detracting from the doctor's clinical freedom. Whether or not he was influenced by costs would be entirely up to him; his autonomy would be unimpaired. A more important question from the point of view of clinical freedom is whether and to what extent doctors are prevented from doing something they wish to do for their patients, by an authoritarian embargo, based on resource considerations, which is in conflict with their professional judgment."

This comes close to saying that only doctors have the right to determine what the effect of resource constraints should be (which, if true, might explain why clinical freedom is invoked against health economists, who also think they have something to say about how best to respond to resource constraints). But this does not appear to be Hoffenberg's intention for he goes on to consider prescribing of the limited list and the carefully controlled dissemination of heart transplantation in the United Kingdom as cases where, despite "the authoritarian encroachment on clinical freedom" there seems to have developed "... a widespread acceptance by the public as well as the profession that resources are not unlimited and that the doctor has a responsibility to Society - through a thoughtful allocation of scarce resources-as well as to the individual patient."

\section{Enter health economics}

It is here that I want to give health economics a more central role in the debate. It seems to me that much of the public and, indeed, some of the professional discussion of resource constraints is bedevilled by the feeling that the extension of life, the relief of pain and suffering, and the improvement in people's functional 


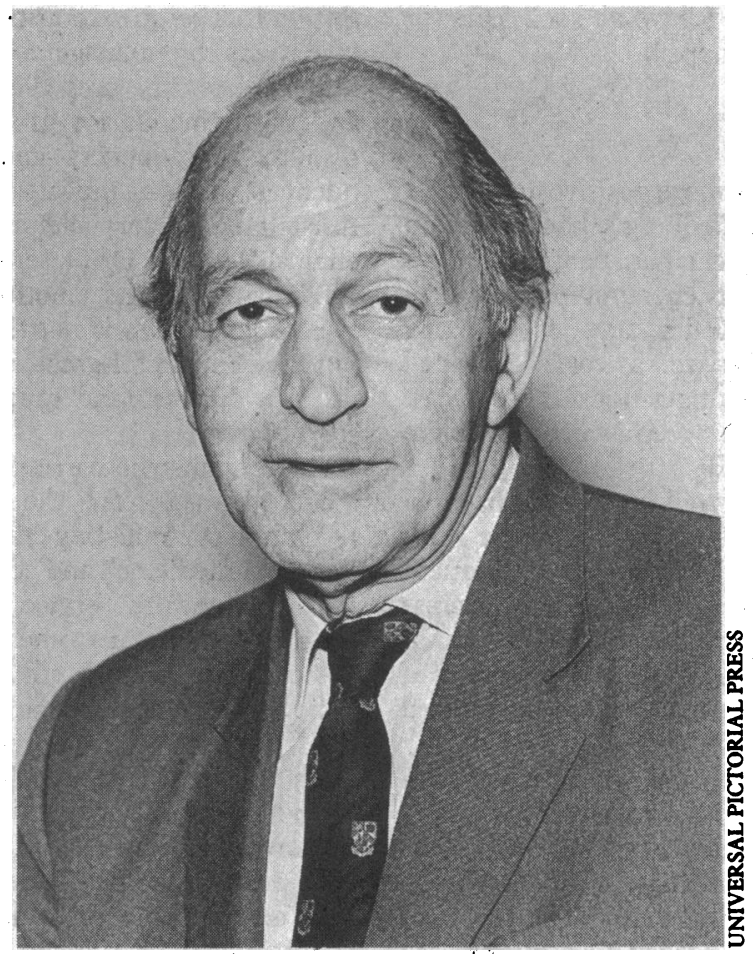

Sir Raymond Hoffenberg

capacity, which the right health care can provide, should not be limited merely by shortage of money or distorted by purely financial considerations. But in economics (unlike accountancy) there is more to the notion of costs than the spending of money. Economics is based on the principle that a "cost" is simply a foregone benefit, so when we advocate greater efficiency we are advocating the adoption of two ethical precepts: firstly, make sure that the sacrifices entailed in pursuing any activity are kept to a minimum, and secondly, make sure that no activity is pursued unless the benefits gained outweigh the benefits foregone.

In applying these general precepts specifically to medical care their implication is that the true cost of treating one patient is the benefit that might have been enjoyed if those same resources had been used to treat other patients. The cost of keeping one patient on hospital haemodialysis for a year is (say) 10 coronary artery bypass grafts foregone. The finance required for each activity is but a superficial mediating variable that should not be allowed to obscure the fundamental choice, which is the one stated. Does "clinical freedom" include the freedom of the renal physician to deny 10 heart patients their bypass grafts (or vice versa for the cardiologist)? This is the agonising reality that underlies the tension between "clinical freedom" and "social responsibility," and I cannot accept that the speed with which this "social responsibility" permeates the NHS should be limited by what Hoffenberg calls "clinical autonomy" - that is, by the willingness of the medical profession to accept this wider responsibility - and by their willingness to act accordingly - not just to accept it grudgingly or resentfully.

The health economist's notion of "cost as sacrifice" (rather than cost as financial expenditure) also shows more clearly the ethical issues underlying the "clinical freedom" $v$ "health economics" discussion. To return to the earlier example, in deciding whether the treatment of the renal patient should be sacrificed to enable the 10 heart patients to be treated or vice versa, we need a distributive ethic, or an ethic of fairness, and this has to be a society wide principle (or set of principles), preferably deeply ingrained in all citizens and in the professions that serve them.

I think Hoffenberg is right in believing that in
Britain we are feeling our way to a large extent unconsciously towards what he calls a "curious, unstated and ill-defined understanding" of that kind. The health economists are trying to sharpen up and clarify the nature of that understanding, especially through the development of generalised measures of health benefit, such as the quality adjusted life year, leading to the suggestion that treatments for which the "cost per quality adjusted life year gained" is very high should be given low priority, so long as we have so many patients waiting for treatments where the cost per quality adjusted life year gained is quite low. To put it more crudely, hip replacements are a better buy than heart transplants.

\section{Legal concepts}

Recently I noted that even the American courts are moving towards a similar criterion when determining whether it would be proper to initiate treatment or to withdraw treatment once initiated. The key legal concept is that of "proportionality," and the relevant dictum is: "Proportionate treatment is that which, in the view of the patient, has at least a reasonable chance of providing benefits to the patient which outweigh the burdens attendant to that treatment."

The court suggested that a benefit exists when life sustaining treatment contemplates "at very least, a remission of symptoms enabling a return toward a normal functioning, integrated existence." Or, as I would put it, when the expected gain in quality adjusted life years justifies the costs.

In reviewing that difficult territory the Stanford University Medical Center Committee on Ethics made the following general observation, ${ }^{4}$ which is central to my theme: "A basic principle of medical ethics is obviously the preservation of life, which is frequently tempered by the second principle, the alleviation of suffering. A third is the injunction that physicians 'first do no harm... . A fourth principle [is] respect for the autonomy of the individual patient.... A fifth fundamental principle is the concept of justice, exemplified by the effort to ensure that medical resources are allocated fairly. The final principle is truth-telling.... Because medical practice often brings these principles into conflict, resolving such conflicts is central to the art of medicine."

But it is also central to the art of health service management, which operates across a much broader range of choice than that facing any individual clinician, and which has a stronger claim to legitimacy than any clinician has when it comes to judging what broad social responsibility entails.

So where does all this leave us as regards the alleged conflict between health economics ' and clinical freedom? According to Hoffenberg there ain't no such animal as clinical freedom in any absolute sense. According to Hampton clinical freedom died a while back, but since it should have been strangled at birth anyway we don't need to mourn its passing. Yet the symbolic power of this apparent myth seems undiminished, and my reading of the situation suggests that it owes this power to its malleability. It is consistent with whatever clinicians choose to make it consistent with.

If I am right in my diagnosis the immediate task of health economists is to get our notions of efficiency and fairness in the distribution of the benefits of health care so deeply embedded in the clinical consciousness that they come to be thought of as wholly within the realm of clinical autonomy, and we outsiders then become redundant. I would be fearful of working myself out of a job by delivering lectures such as this if I thought that all doctors were as receptive to this way of thinking, talking, and acting as the Hamptons and Hoffenbergs 
of this world clearly are. But I have no such fears (or perhaps I should say no such hopes).

\section{Accountability}

I would like now to strike a more positive note, and I found one in Raymond Hoffenberg's book. As you would expect from someone who has spent most of his professional life simultaneously encouraging doctors to count costs as well as benefits, and encouraging managers to count benefits as well as costs, I jumped with joy when I came across this delightful passage in which Hoffenberg manages to sweep away the problem and leave us all on the same side:

"Doctors are best placed to shift the emphasis of managerial enquiry from its pre-occupation with resources and costs to health outcome or patient satisfaction. For this reason alone medical participation in management is imperative. By ensuring that resources are devoted optimally to serve the interests of patients, doctors will find that their own clinical freedom is maximised."

So health economics actually enhances clinical freedom. There seems nothing more to be said. I just wish I could believe it. But I think that Hoffenberg has muddled up two different things. He is right in believing that if doctors absorb into their realm of action the managerial skills needed to minimise the potentially adverse effects of resource constraints their clinical practice will thereby be improved. But this does not mean that their clinical freedom has been enhanced; indeed, quite the reverse. I think Hoffenberg has been too concerned to allay the fears of his colleagues, and in resolving this ethical dilemma he has given too much weight to the relief of distress and too little to truth telling. So let me end by shifting the weight the other way.

Much of the tension between health service managers and the medical profession (and I do not mean between the government and the NHS, which is a different matter) revolves around the issue of who has the authority to decide and give effect to the priority setting that resource constraints make inevitable. The incursions by management into territory that has hitherto been the preserve of the medical profession, and the demands for greater accountability for the resource consequences (and even for the health consequences) of their clinical activities, are still frequently resisted by doctors sheltering behind the banner of clinical freedom. On closer scrutiny the banner may be threadbare, but its emotional appeal is still strong. Health economics is not the end of clinical freedom, but the demand for greater accountability for resource use is a further (and quite proper) limitation of its scope.

A more constructive response by doctors would be to move forward from the key observation that the resolution of conflicting ethical principles is "central to the art of medicine" and accept that it is also central to the art of health service management, and in that broader forum many other voices are equally entitled to be heard. Doctors still have an important role in policy making at national, regional, district, and unit level. But theirs is not a pre-eminent role, or one which gives them the right to exclude others from any part of the policy discussion in the name of clinical freedom or on any other pretext. It is an agonising realm of discourse, which because of its very nature cannot be easy intellectually to think through, or comfortable emotionally to implement, so it needs to be approached with great sensitivity, and respect for the views of others, remembering all the time that none of us has a hot line to God. And on that celestial note I end this diabolical discussion.

1 Hampton JR. The end of clinical freedom. Br Med $\mathcal{f} 1983 ; 287: 1237-8$

2 Loewy EH. Cost should not be a factor in medical care. $N$ Engl f Med 1980;302:697.

3 Hoffenberg R. Clinical freedom. London: Nuffield Provincial Hospitals Trust, 1987:ix,x,13,18,35.

4 Barber $v$ Superior Court 1983. Cited in Ruark JE, Raffin TA and Stanford University Medical Center Committee on Ethics. Initiating and withdrawing life support: principles and practice in adult medicine. $N$ Engl $\mathcal{Y} \mathrm{Med}$ 1988;318:25-30.

(Accepted 22 fuly 1988

\section{ANY QUESTIONS}

\section{Is an objective assessment possible of the effects of adult smoking on children?}

The results of many studies on the effects of passive smoking have recently been summarised in the Froggatt report. These show that passive smoking in children is associated with increased respiratory symptoms, episodes of respiratory illness, and reduced ventilatory function.

Several biochemical markers have been used to discriminate between smokers and non-smokers, and these may be used as objective assessments of exposure to passive smoking in children. A recent study comparing the various biochemical tests found that the concentration of cotinine, whether measured in plasma, saliva, or urine, was the best indicator of smoking, with a sensitivity of $97 \%$ and specificity of $99 \%$. Comparisons with the cotinine concentrations in the saliva of children who smoke show that in a household where both parents smoke the children are receiving a concentration of nicotine equivalent to 80 cigarettes a year. Concentration of carbon monoxide measured as blood carboxyhaemoglobin or in expired air gave slightly poorer sensitivity and specificity (around $90 \%$ ). A carbon monoxide monitor is, however, effective for routine use in hospital or general practice and is considerably cheaper and simpler to apply than cotinine tests. In adults it verifies whether a patient is smoking or not, while an abnormal reading in children can be used as a basis for health education advice. These meters are available from Action on Smoking and Health (ASH) at a cost of a few hundred pounds.

Apart from the physical effects of parental smoking in increasing the probability of disease substantial evidence from studies in Britain and Norway shows that children are more likely to take up smoking if their parents, teachers, older siblings, or schoolfriends smoke. They are also greatly influenced by tobacco advertising. These effects on their future behaviour are perhaps at least as important as the direct ill effects of tobacco smoke. - HELEN DUNFORD, senior health education officer, and NOEL D L OLSEN, district medical officer, London

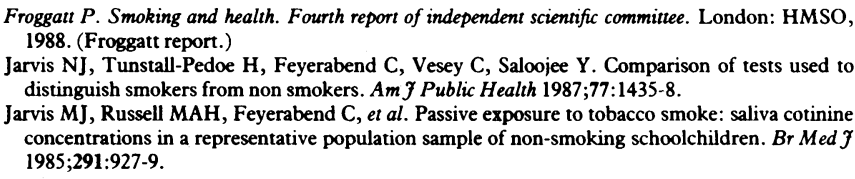
1988. (Froggatt report.)

Jarvis NJ, Tunstall-Pedoe H, Feyerabend C, Vesey C, Saloojee Y. Comparison of tests used to distinguish smokers from non smokers. Am f Public Health 1987;77:1435-8.

Jarvis MJ, Russell MAH, Feyerabend C, et al. Passive exposure to tobacco smoke: saliva cotinine concentrations in a representative population sample of non-smoking schoolchildren. $\mathrm{Br} \mathrm{Med} \mathcal{J}$ 1985;291:927-9.

Could the chemicals used in dry cleaning cause dermatitis to those wearing cleaned garments?

Yes in theory but not in practice. The solvents used in coin operated and commercial dry cleaning processes are derivatives of chloroethylene - that is, perchloroethylene, trifluorotrichloroethylene, or trichloroethylene. All are primary irritants but extremely volatile. When cleaning is complete the amount left on commercially cleaned garments is extremely small and wil have fully evaporated a short while after removal from the closed machines. Although contact dermatitis has occurred in workers operating the equipment, no cases have been reported from wearing cleaned clothes. Other chemicals used in the process - waxes and resins for retexturing and fabric softeners - have not been reported as producing dermatitis. - ALAN B SHRANK, consultant dermatologist, Shrewsbury

Cronin E. Contact dermatitis. London: Churchill Livingstone, 1980 